\title{
THE EFFECT OF THE DEMAND-CHANGES ON THE INVENTORIES
}

\author{
János Korponai ${ }^{\mathrm{a}}$, Ágota Bányainé Tóth ${ }^{\mathrm{b}}$, Béla Illés ${ }^{\mathrm{c}}$ \\ ${ }^{a} M S c$, PhD student, University of Miskolc, H-3515 Miskolc-Egyetemváros, Hungary \\ ${ }^{b} \mathrm{PhD}$, University of Miskolc, H-3515 Miskolc-Egyetemváros, Hungary \\ 'Professor, University of Miskolc, H-3515 Miskolc-Egyetemváros, Hungary
}

\begin{abstract}
When the future customer demands can be exactly quantified, the level of the closing stock, the quantity of the placed order and the actual date of the order can be clearly defined with the knowledge of the initial stocks, the production demand and the restocking of supplies. However, this initial condition is very rare in practice. There are several unpredictable factors influencing the stock level that will affect the operation of the production company. The objective of the logistics management is to guarantee the stock level required for the adequate handling of production at the lowest possible level of costs. The definition of the service level provides an opportunity to handle the fluctuation of demands due to different impacts with a predetermined safety, and to quantify the stock level required for the operation.
\end{abstract}

Keywords: change of demands; safety stock; stochastic; standard normal distribution; random variable
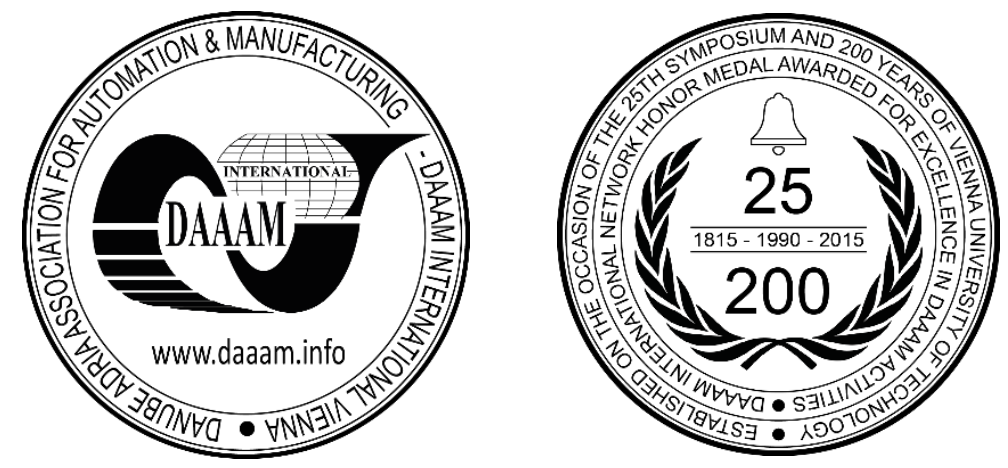

This Publication has to be referred as: Korponai, J[ános]; Banyai, A[gota] \& Illes, B[ela] (2016). The Effect of the Demand-Changes on the Inventories, Proceedings of the 26th DAAAM International Symposium, pp.1068-1075, B. Katalinic (Ed.), Published by DAAAM International, ISBN 978-3-902734-07-5, ISSN 1726-9679, Vienna, Austria DOI: $10.2507 / 26$ th.daaam.proceedings. 150 


\section{Introduction}

Our theories applied in the case of the economic order quantity are influenced by the fact that the customer demands are not completely known, and disturbances can occur in our processes that together create an uncertainty regarding the intensity of demands for purchased parts and the development of the stock level.

During the definition of our supply management strategy, we can choose from two basic models, thus we have to separate the continuous and the periodic review systems. In case of a continuous review, the order quantity is constant, thus the uncertainty affects the level of the closing stock at the end of the periods; while in the case of a periodic review, there are fixed times between the orders, thus the uncertainty affects the order quantity [1].

By walking around the periodic review model during our analysis, we will present the relations between the fluctuation of demand and the safety stocks, and we will define the formula for the quantification of the safety stock.

\section{The relationship between the deterministic and stochastic changes of demands and the stock level}

As a simplified model, figure 1 shows the inventory mechanism and the modification of stocks in case of a deterministic demand and stock replenishment. The initial conditions of the model include the continuous use at a steady pace, a steady $t$ periodic supply, the minimum stock level $Q_{\text {min }}$ equal to zero starting from the inadmissible stock shortage and the zero safety stock, and the $Q$ reorder quantity until the admissible $Q_{\max }$ maximum stock level. The calculable $\tau$ replenishment time and the $t_{i}$ date of receipt determine the latest $t_{r}$ date, when the order must be placed [2]. The $Q_{r}$ stock level assigned to time $t_{r}$ represents the minimum stock level that covers the usage within the time period necessary from the placement of the order until the actual receipt of the ordered quantity [3] [4].

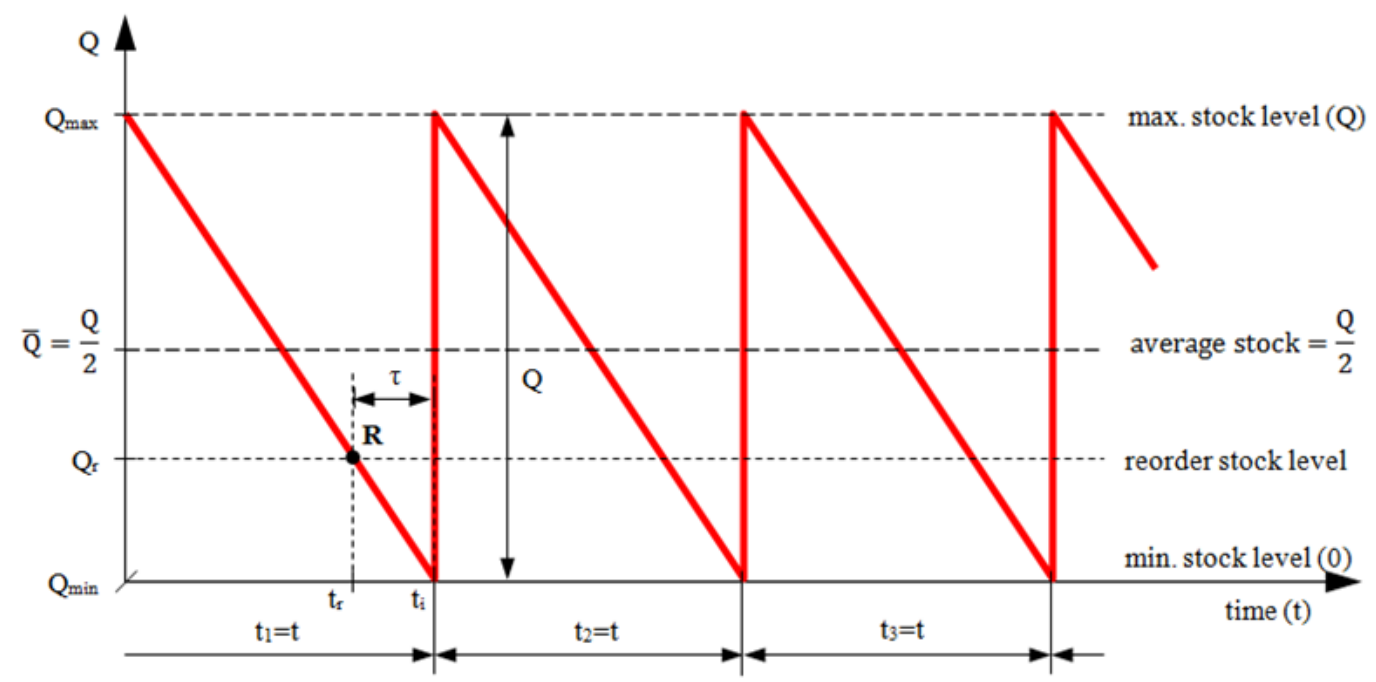

Fig. 1. Development of stock level in case of deterministic demand and replenishment time

Furthermore, the initial conditions of the model include the fact that the time demand of stock replenishment is shorter than the periodic time $(\tau<t)$, meaning that maximum one supply can be in progress at a given moment. This simplified model shows that the maximum stock level is equal to the quantity per order $\left(Q_{\max }=Q\right)$, the stock drops to zero at the end of the period $\left(Q_{\min }=0\right)$, thus the average stock can be defined with the following formula [5]:

$$
\bar{Q}=\frac{Q_{\max }-Q_{\min }}{2}=\frac{Q}{2}
$$

By using the principle of ceteris paribus, we carry out the analysis by emphasizing one initial condition of the model, the development of the utilization demand. In this case, the model changes to the extent that we allow a deviation in any direction and of any extent between the demands of the different periods, by specifying that the demand of the respective period is continuous and constant within the period (almost stationary) [2].

By showing demands of the same time periods and different extents, figure 2 shows that, compared to figure 1 , in case of increased demand the stock level can drop below the former level $Q_{\min }=0$. In case of a supply management strategy that does not allow a stock shortage, this means in practice a shift of the $Q_{\min }$ level towards the value $Q_{\min }{ }^{\prime}=0$. In order to simplify the model and by applying the principle of ceteris paribus once again, the maximum restocking level $Q_{\max }$ is constant, thus the replenishment of the closing stocks of different periodical extents to the maximum stock level assumes a reorder quantity $Q_{n}$ of a different extent [6] [9]. 


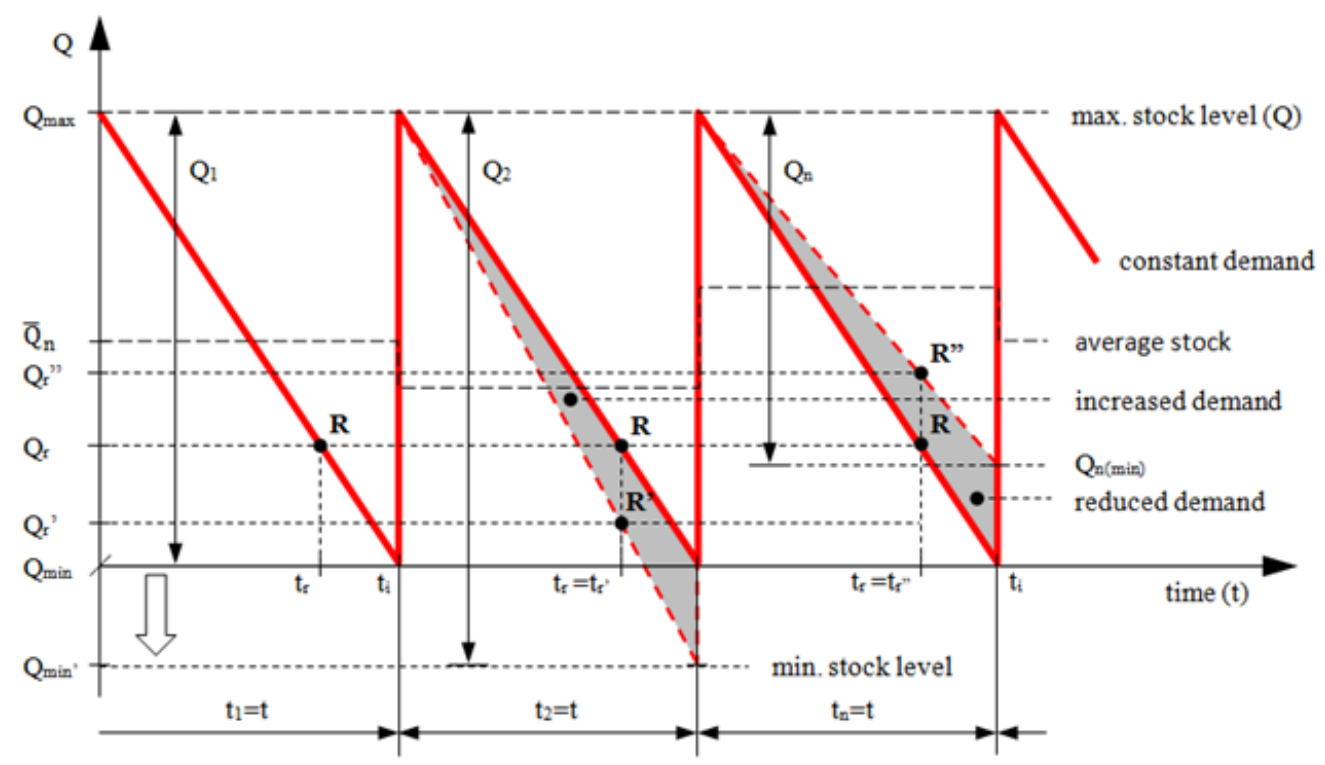

Fig. 2. The relationship between utilization demands of different extents and stock levels

In case the stock level $Q_{\max }$ is identical in each period during the modelling and we do not allow stock shortages, the $Q_{\min }$ ' level must be drawn to the lowest point of the saw tooth diagram by adjusting to the highest intensity of utilization. In periods when the closing stock at the end of the period does not reach the lowest $Q_{\min }$ ' level defined for the analysed period, the extent of the remaining stock will be $Q_{\max }-Q_{\min }{ }^{\prime}-Q_{n}=Q_{n(\min )}-Q_{\min }$ '. The average stock of the respective period can be defined as follows:

$$
\bar{Q}_{n}=\frac{Q_{\max }-Q_{n(\min )}}{2}+Q_{n(\min )}-Q_{\min }{ }^{\prime}=>\frac{Q_{\max }+Q_{n(\min )}}{2}-Q_{\min }{ }^{\prime}=\frac{Q_{n}}{2}+Q_{n(\min )}-Q_{\min }{ }^{\prime}
$$

The average stock for the analyzed period:

$$
\bar{Q}=\sum_{n=1}^{m}\left(\frac{Q_{\max }+Q_{n(\min )}}{2}-Q_{\min }{ }^{\prime}\right)=\sum_{n=1}^{m}\left(\frac{Q_{n}}{2}+Q_{n(\min )}-Q_{\min }{ }^{\prime}\right)=\sum_{n=1}^{m} \frac{\bar{Q}_{n}}{n}
$$

In this case, the change of demands is planned, thus it shows deterministic features. However, it is very often the case that the demand of the next period or periods deviates to a certain extent and in a certain direction from the planned level within a short deadline, or even within the period. In order to simplify the model, we take the change of demands within the respective period into account, but we calculate with a constant demand within the full period, meaning that during the monitoring of the change we consider only the extent of the opening and closing stock, and we assume a utilization of constant intensity within the period [7].

In practice, the deviation from the plan can be attributed to several root causes, e.g. unexpected change of customer demands, excess consumption in production due to scrap, stock deviation at some point of the supply chain, stock blocking due to quality claims, etc.

The order point of stocks on figure 2 must be redefined. As an initial condition, we defined that the lead time of replenishment is predefined and the order time is defined at the latest date possible. In case we would order when reaching the level of the original minimum stock, in some cases the ordering and the receipt of stocks would happen too soon, and in some cases it would lead to delays. Based on the predetermined lead time, the minimum stock level will change from period to period, adjusting to the actual utilization intensity of the respective period.

In case of an analysis of an adequate number of samples, the deviations will be typically situated along the probability density function of a standard normal unimodal distribution (figure 3). In case the partners have agreed on a maximum number of allowed deviations, the respective range of accepted deviations can be defined in the form of lower and upper tolerance values [8]. The well-known distribution and density functions popular in production management and quality management circles for the presentation of quantity features of certain products can be used in logistics as well. With them, we can show the standard deviation of the actual utilization from the plan, the situation of deviations compared to the target, the distribution of deviations, the intervention points or tolerances, and the range of the changing utilization demands.

Contrary to the deterministic management models, in case of stochastic models, the utilization is influenced by accidental factors, thus the material requirement can be defined only with random variables. 


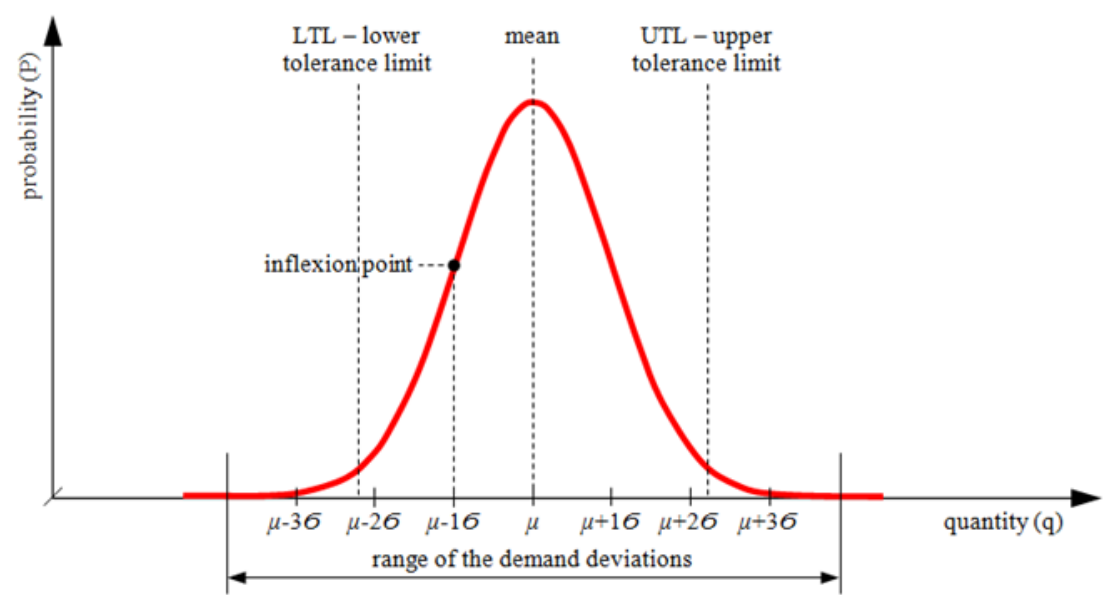

Fig. 3. The probability density function of the standard normal distribution and its features

\section{Periodic review in case of stochastic change of demands}

In order to simplify the model, hereinafter we will assume demand changes with symmetric standard normal unimodal distributions. The simplified stock management model showed on figure 1 and characterized with a deterministic stock replenishment time and a utilization with constant intensity can be completed with the maximum extent of the demand change in two directions, so that figure 4 is modelling the deviations occurring compared to the planned utilization. Since the direction and extent of the deviation compared to the plan is stochastic, i.e. it cannot be exactly defined in advance, thus the development of the actual utilization demand and of stocks can be determined only with random variables that are represented on the figure by the probability density functions of the standard normal distribution.

In case we only keep stocks to cover the planned demands, according to our stock management strategy, the increase of the actual utilization demand compared to the plan would result in a drop to zero of the stocks before the $t_{i}$ date of receipt. This is inacceptable in case we start from a strategy that does not allow a stock shortage, a certain amount of safety stock $\left(Q_{s s}\right)$ should be kept in order to avoid the risks and costs due to excess consumption.

Since the fluctuation of demands has a stochastic character, the possible results are random variables equivalent to the standard normal distribution. Figure 4 shows that if the demand is a random variable, the occurrence of extreme demands has a very low probability, thus the stock shortage can be most likely avoided only with a safety stock with an infinite high level. In practice however, this is not feasible due to different economic efficiency reasons, thus a compromise must be reached between the consequences caused by the stock shortage and the sacrifices brought to avoid the shortage [10] [11].

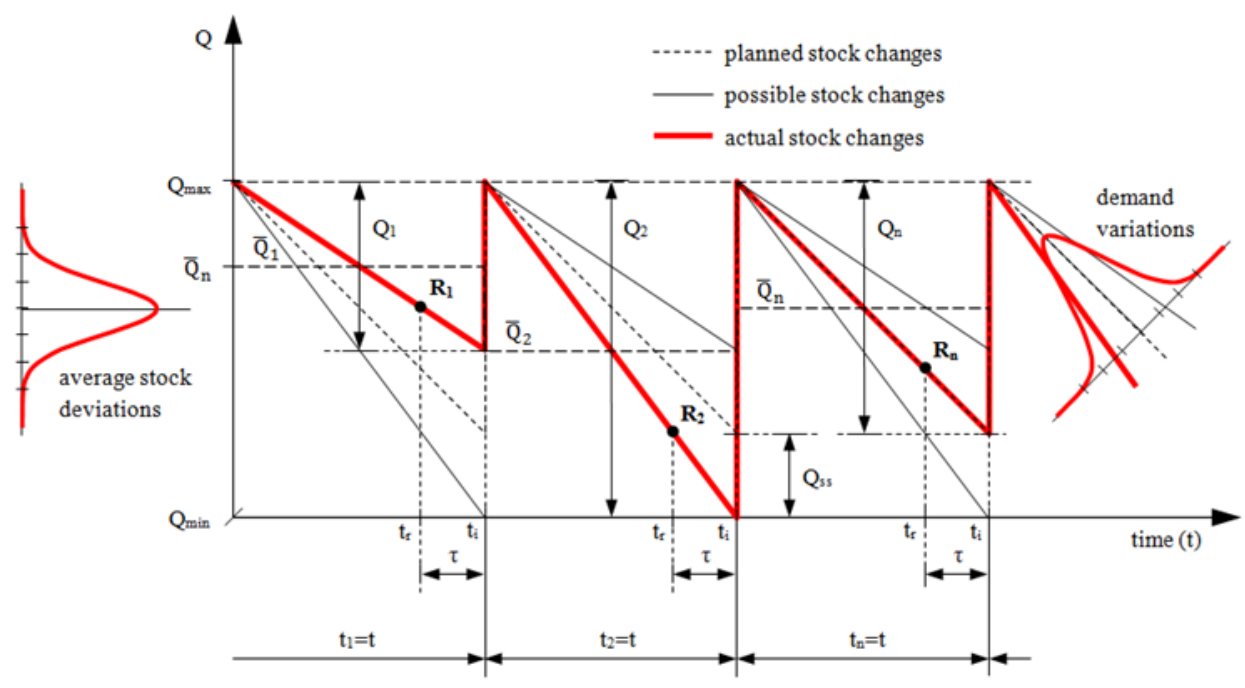

Fig. 4. Periodic review in case of stochastic change of demands

The density function detailed on figure 5 shows the probability of occurrence of actual quantities, which reflects that the frequency of occurrences is more typical around the expected value, while their probability decreases towards the two ends of the function [12] [13]. 


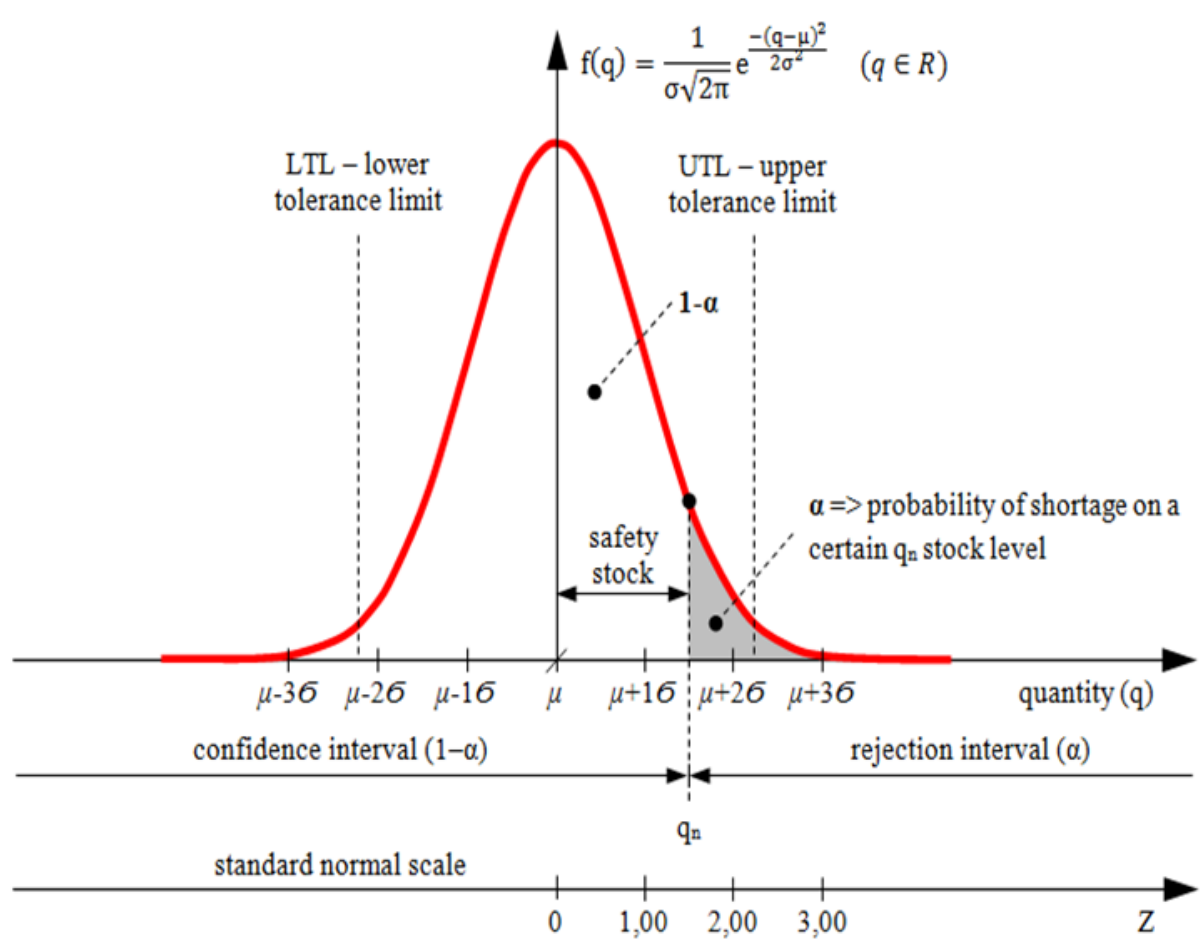

Fig. 5. The effect of the safety stock on the occurrence probability of the stock shortage

The figure shows clearly that the extent of the given stock level covering the demand can be defined in relation to any arbitrary $\mathrm{q}_{\mathrm{n}}$ stock level and the actual demand. The stock level above the actual demand is the safety that covers the fluctuation of demands. The safety stock level can be calculated with the following formula:

$$
Q_{s s}=q_{n}-\mu
$$

where

$Q_{s S}$ - safety stock level,

$\mu-$ actual demand, or the expected demand value,

$q_{n}-$ arbitrary stock level.

The formula above demonstrates that the safety stock can have a negative level, if we allow the probability of the occurrence of a stock shortage during our stock management strategy to reach an extent where the stock we keep in certain periods is not enough to cover the planned demands:

$$
q_{n}<\mu \text { in case of } Q_{s s}<0
$$

In the knowledge of the standard deviation and the expected value, the probability of the occurrence of a shortage can be defined in relation to any utilization demand and stock level. In case we adjust the stocks only to the planned demand level, i.e. we do not keep a safety stock $\left(q_{n}=\mu\right)$, the probability of the occurrence of a shortage in case of a demand with standard normal distribution will correspond to the probability of the non-occurrence of the shortage (figure 6). Since the combined probability of the two possible results is $100 \%$, the following relation is valid:

$$
P_{(\text {shortage })}=P_{(\text {coverage })}=0,5
$$

The distribution function on figure 6 shows the probability of the coverage of demand fluctuations in relation to the changes of the stock level. The probability of the occurrence of the shortage decreases proportionally with the increase of the safety stocks; however, the complete safety can be guaranteed only by a stock with an infinite level. The introduction of the distribution function is justified by the fact that the function reflects well the probability of the occurrence of the stock shortage in connection with the stock level. The probability can be expressed as a risk as well, to which actual costs can be assigned.

When determining the order quantity due for the next period and the stock level guaranteeing a continuous operation, five tasks must be completed. 
1. The service level of our stock management strategy has to be defined, i.e. the frequency of shortage acceptance

2. The level of the utilization demand planned for the next period has to be defined

3. By considering the expected fluctuation of the service level and the utilization demand, the stock level guaranteeing the avoidance of the shortage's occurrence has to be defined

4. The extent of the probable demand due by the end of the period between the ordering point and the receipt of products has to be quantified

5. It must be checked whether the stock available at the moment of the order covers the demand until the period's end, and its expected fluctuation.

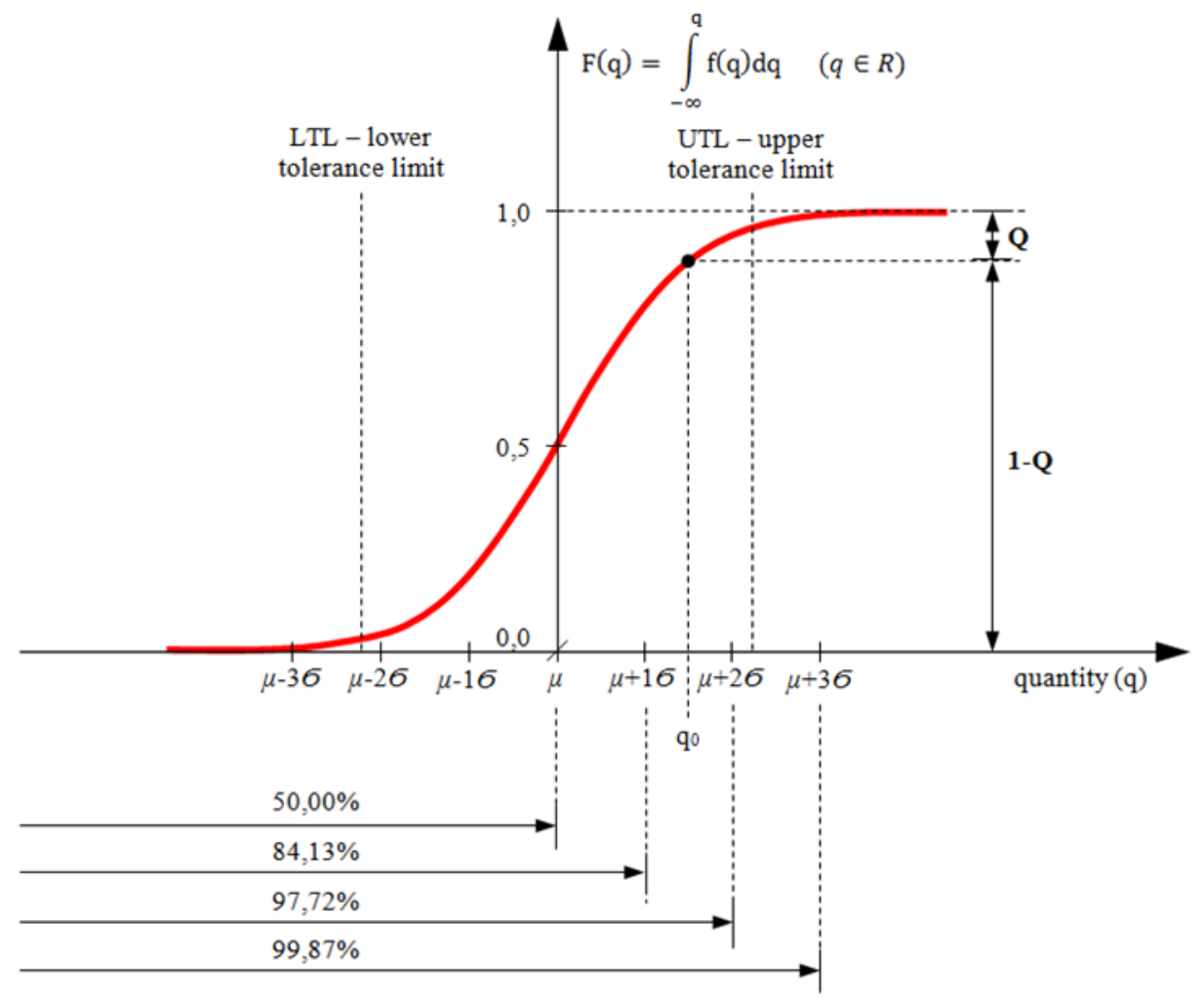

Fig. 6. The probability of the coverage of demand fluctuations in relation to the change of the stock level

Under service level we mean the extent of acceptance regarding the shortage, which can be defined in two ways [1]. It can be determined as a relation of the number of periods allowing shortages and the total number of periods analyzed, or we can define the allowed probability of the occurrence of the shortage. In case we allow 2 periods uncovered by stocks for a complete period, e.g. one year, the service level can be defined by a weekly period as follows:

$\frac{S L \times t}{T}=\frac{2 \times 7}{360}=0,0389$

W where

$S L$ - service level,

$t$ - the length of a given period,

$T$ - the length of the complete period.

From the standard normal distribution table we get the value $\mathrm{Z}=1.765$ matching the probability value 0.0389 . Another way to define the service level is to define the maximum allowed level of the probability of the shortage's occurrence (e.g. 0.02) and to find the matching $\mathrm{Z}=2.33$ value. Irrespective of the definition of the service level, we apply the resulting value in a consistent way.

Subsequently, we must define the utilization demand expected for the next period:

$$
\mu=t \times \bar{d}_{t}
$$

where

$\mu$ - the expected value of demand,

$\bar{d}_{t}-$ average level of demand during the given period. 
The fluctuation expected for the duration of the next period can be defined based on the service level and the expected demand value. By using the formulae of the density function and the distribution function (11), we can determine the $F(q)$ value of the distribution function for any arbitrary $q$ value [14] [15] [16]:

$$
f(q)=\frac{1}{\sigma \sqrt{2 \pi}} e^{\frac{-(q-\mu)^{2}}{2 \sigma^{2}}} \rightarrow F(q)=\int_{-\infty}^{q} f(q) d q=\frac{1}{\sigma \sqrt{2 \pi}} \int_{-\infty}^{q} e^{\frac{-(q-\mu)^{2}}{2 \sigma^{2}}} d q=\Phi\left(\frac{q-\mu}{\sigma}\right)
$$

In case the value of the standard normal distribution function is equal to the service level, the stock level $q$ barely covers the expected utilization demand $\mu$ that can be characterized with an $\sigma$ standard deviation by an $S L$ reliability level:

$$
F(q)=\Phi\left(\frac{q-\mu}{\sigma}\right) \rightarrow \Phi\left(\frac{q-\mu}{\sigma}\right)=S L
$$

Formula (12) shows that the $Q_{s s}$ safety stock level belonging to the $S L$ service level is the difference of the stock level and the expected demand level $q-\mu$, which can be defined with the help of the standard normal distribution $\Phi(q)$ table.

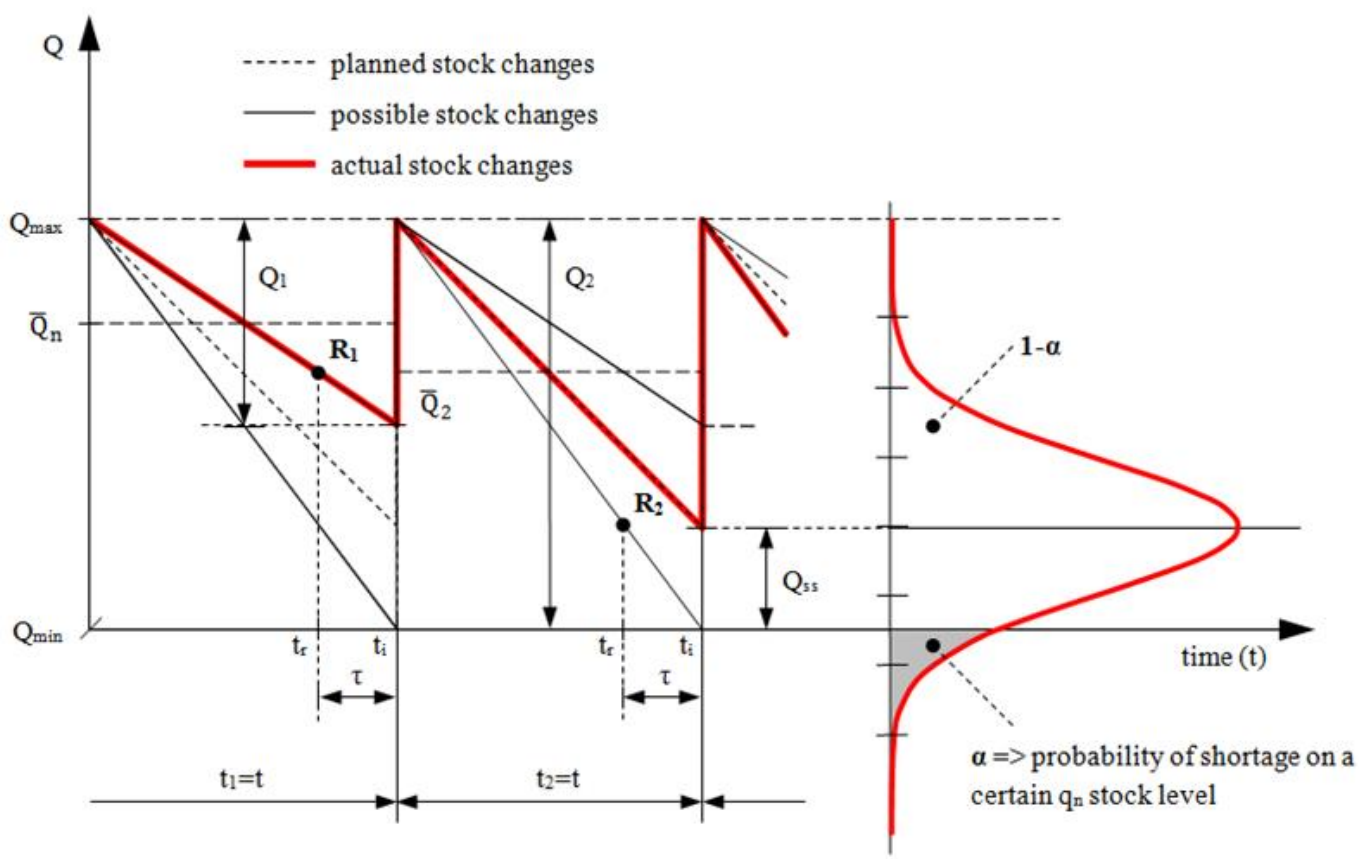

Fig. 7. The relations of the periodic review

The extent of the expected demand due by the end of the period between the ordering point and the receipt of products can be quantified similarly to formula (10):

$$
\mu_{\tau}=\tau \times \bar{d}_{\tau}
$$

where

$\mu_{\tau}$ - expected value of demand due within the stock replenishment period,

$\tau$ - lead time of stock replenishment,

$\bar{d}_{\tau}$ - average demand of the period between the ordering point and the period's end.

In case of a periodic review, it is not only the next period's demand and the probable change of demands that need to be calculated during the placement of the order, but we also have to consider the extent of the change of demands expected for the remaining $\tau$ duration of the ordering period. Figure 7 demonstrates the above-mentioned relations [1].

Since the expected value of the utilization demand and the fluctuation of utilization are random variables due to the impact of future events with unpredictable outcomes, the development of the $Q_{\max }$ stock level will be a random variable as well. The probability of a maximum stock level of a given period to be equal to the planned $Q_{\max }$ stock level, is equal to the difference of the $F(q)-F(\mu)$ probabilities, i.e. $P(q=\mu)$. 


\section{Conclusion}

The more stringent expectation we define towards the frequency of stock shortages in our stock management strategy, the higher the expenses will be for the avoidance of the stock shortage. Fundamentally, we can guarantee the achievement of the target level in two directions:

- We can decrease the uncertainty of the demand fluctuation with a more accurate forecast.

- We can increase the safety stocks to cover the fluctuating demands.

The management of utilization demand changes of unpredictable extents urges the management of the production company to reach a compromise. The shortage of stocks can cause serious disturbances in the production supply and customer service, the costs of which are often unquantifiable. The avoidance of stock shortages is an important objective for every organization; however, it would be possible only with the management of an infinite stock level due to the stochastic nature of demands. Stock management also has costs, thus the definition of an optimum stock level is a task for an enterprise, where the combined costs of stock management and stock shortage show the lowest possible level.

\section{Acknowledgements}

This research was partially carried out in the framework of the Centre of Excellence of Logistics, Information Technology and Mechatronics at the University of Miskolc.

\section{References}

[1] Koltai T., Production Management. Typotex Publisher. Budapest (2009)

[2] Cortinhal, M. J., Lopes, M. J., Melo, M. T.: Dynamic design and re-design of multi-echelon, multi-product logistics networks with outsourcing opportunities: A computational study, Computers \& Industrial Engineering 90 (2015) 118-131.

[3] Accorsi, R., Manzini, R., Maranesi, F.: A decision-support system for the design and management of warehousing systems, Computers in Industry 65(1) (2014) 175-186.

[4] Stockton, D. J., Quinn, L., Identifying economic order quantities using genetic algorithms, International Journal of Operation \& Production Management 13 (1993) 92-103.

[5] Ceniga, P., Sukalova, V.: Future of Logistics Management in the Process of Globalization, Procedia Economics and Finance 26 (2015) 160-166.

[6] Aguezzoul, A.: Third-party logistics selection problem: A literature review on criteria and methods, Omega 49 (2014) 69-78.

[7] Stock, J. R., Lambert, D. M., Strategic Logistics Management, McGraw-Hill Higher Education, Boston (2001)

[8] Kralikova, R., Rusko, M., Wessely, E., Framework for Applying Six Sigma Methods within Environmental Management, Chapter 45 in DAAAM International Scientific Book 2012, pp. 545-552, B. Katalinic (Ed.), Published by DAAAM International, ISBN 978-3-901509-86-5, ISSN 1726-9687, Vienna, Austria, DOI: 10.2507/daaam.scibook.2012.45.

[9] Chopra, S., Meindl, P., Supply Chain Management: Strategy, Planning, and Operation , Pearson Prentice-Hall Publishers, New York (2007)

[10] Vörös J., Production and service management. Akadémia Publisher, Budapest (2010)

[11] Dania, W. A. P.: Application of Genetic Algorithms in Inventory Management, Chapter 25 in DAAAM International Scientific Book 2010, pp. 245-258, B. Katalinic (Ed.), Published by DAAAM International, ISBN 978-3-90150974-2, ISSN 1726-9687, Vienna, Austria DOI: 10.2507/daaam.scibook.2010.25.

[12] Kulcsár B., Industrial logistics, LSI Teaching Center, Budapest (1998)

[13] Kummer, S., Grün, O., Jammernegg, W., Basics of purchasing, production, logistics. Pearson Studium, München (2009)

[14] Jaynes, E. T.: Probability theory: The logic of science, Cambridge University Press, Cambridge (2003)

[15] Browder, A.: Mathematical analysis - an introduction, Springer, Berlin (1996)

[16] Triola, M. F.: Elementary statistics, Pearson Education (2013) 